\title{
Preparation of chemical waste germanium concentrates for disposal
}

\author{
(C) Igor N. Tanutrov, ${ }^{*}$ and Marina N. Sviridova ${ }^{+}$ \\ Institute of Metallurgy of Ural Branch of Russian Academy of Sciences. \\ Amundsen St., 101. Ekaterinburg, 620016. Russia. \\ Phone:+7 (904) 380-56-57.E-mail: intan38@live.ru
}

\begin{abstract}
*Supervising author; ${ }^{+}$Corresponding author Key words: waste, germanium concentrate, chemical processing, waste, preparation, disposal.
\end{abstract}

\begin{abstract}
The composition of waste from chemical processing of germanium concentrates (WCGC) is characterized by the presence of germanium compounds insoluble in acids, as well as significant amounts of toxic impurities. The main phase components are calcium sulfate dihydrate and four-water calcium hypochlorite. Thermographic research on heating samples of WCGC at $200{ }^{\circ} \mathrm{C}$ in the air found that their heat treatment is accompanied by two endothermic effects corresponding to two successive stages of dehydration at exposure from the beginning of heat treatment to 30 minutes with the removal of free moisture and from 30 to 90 minutes with the removal of 1.5 water molecules from gypsum and 4 water molecules - from calcium hypochlorite.

X-ray phase analysis revealed that the heat-treated samples form calcium sulfate hemihydrate and dehydrated calcium hypochlorite. The presence of these compounds gives a strengthening effect when moistened due to the re-formation of crystallohydpates.

In laboratory conditions, options for pelletizing pre-crushed mixtures of heat-treated WCGC and coke using pelletizing and briquetting methods have been tested. The humidity, density, bulk weight and strength of pellets and briquettes for compression and impact were determined immediately after pelletizing, sevenhour exposure and drying at $105{ }^{\circ} \mathrm{C}$. The research results confirm the possibility of obtaining a material suitable for effective utilization of waste from chemical processing of germanium concentrates.
\end{abstract}

\section{References}

[1] I.N. Tanutrov, M.N. Sviridova. Scientific justification, development and implementation of pyrometallurgical technology for obtaining germanium concentrates. Nonferrous metal. 2014. No.2(854). P.71-75. (russian)

[2] Germanium concentrate. TU 1774-003-95961127-2008.

[3] V.M. Andreev, A.S. Kuznetsov, G.I. Petrov, L.N. Shigina. Production Germany. Moscow: Metallurgy. 1969. 93p. (russian)

[4] M.Ya. Shpirt. Physico-chemical and technological principles of production of germanium compounds. Apatity: Ed. Kola scientific center of the Russian Academy of Sciences. 2006. 286p. (russian)

[5] I.N. Tanutrov, and M.N. Sviridova. Properties of waste of chemical processing of germanium concentrates. Butlerov Communications. 2019. Vol.58. No.6. P.104-109. DOI: 10.37952/ROI-jbc-01/1958-6-104

[6] N.A. Andreeva. Chemistry of cement and binders. St-Petersburg: SPb GASU. 2011. 67p. (russian)

[7] O.V. Nechvoglod, and A.G. Upolovnikova. The study of the phase composition of the products of electrochemical oxidation of sulfide granules of the system $\mathrm{Cu}_{1.96} \mathrm{~S}-\mathrm{Ni}_{3} \mathrm{~S}_{2}-\mathrm{Cu}-\mathrm{Ni}$. Butlerov Communications. 2019. Vol.57. No.3. P.149-154. DOI: 10.37952/ROI-jbc-01/19-57-3-149

[8] S.N. Golovin, M.N. Yaprintsev, I.G. Ryltsova, and O.E. Lebedeva. Influence of nature of the precipitating agent and chemical-thermal treatment on the phase composition of cerium-containing layered double hydroxides. Butlerov Communications. 2018. Vol.56. No.12. P.126-130. DOI: 10.37952/ROI-jbc-01/18-56$12-126$

[9] A.N.Gabdullin, E.A. Nikonenko, T.M. Klyuev, and V.F. Markov. Chemical and phase composition of oxidized nickel ores of the Kulikovsky deposit - raw materials for the production of magnesium compounds, $\mathrm{Fe}-\mathrm{Ni}$-containing concentrates, $\mathrm{SiO}_{2}$. Butlerov Communications. 2018. Vol.55. No.8. P.156161. DOI: $10.37952 /$ ROI-jbc-01/18-55-8-156 
[10] A.E. Buntin, R.O. Sirotkin, and O.S. Sirotkin. Features of chemical structure, properties and technology of inorganic products based on oxides. Butlerov Communications. 2018. Vol.53. No.2. P.153-160. DOI: 10.37952/ROI-jbc-01/18-53-2-153

[11] I.N. Tanutrov, M.N. Sviridova, P.S. Bazhov, L.A. Ovchinnikova. Phase formation in briquetted mixtures of $\mathrm{Ca}(\mathrm{OH})_{2}+\mathrm{Al}(\mathrm{OH})_{3}+\mathrm{CaSO}_{4} \cdot 2 \mathrm{H}_{2} \mathrm{O}+\mathrm{C}+\mathrm{SiO}_{2}+\mathrm{Fe}_{2} \mathrm{O}_{3}$ during their heat treatment. Chemical technology. 2012. Vol.13. No.1. P.1-4. (russian)

[12] A.N. Popova, Ch.N. Barnakov, G.P. Khohlova. The study of the structural characteristics of carbon materials by mean of XRD analysis. Butlerov Communications. 2018. Vol.56. No.11. P.153-159. DOI: 10.37952/ROI-jbc-01/18-56-11-153 